\title{
Identidad y Comunidad en la Fiesta del Jabalí de Aiguá
}

\author{
IDENTITY AND COMMUNITY IN THE FEAST OF WILD BOAR IN AIGUÁ
}

IDENTIDADE E COMUNIDADE NA FESTA DO JAVALI EM AIGUÁ

\author{
Antonio di Candia Cutinella* \\ Juan Martín Dabezies*1 \\ adicandia@gmail.com
}

Recibido: 15/2/2020 Aceptado: 12/9/2020

\begin{abstract}
Resumen
Este trabajo busca conocer el proceso de definición de la identidad en tanto comunidad imaginada del pueblo de Aiguá, Uruguay, durante la organización, gestión y desarrollo de la Fiesta del Jabalí (animal declarado plaga nacional en Uruguay). Son varios los factores que operan en la construcción de la identidad local: la tradición, el combate a la plaga, la pertenencia a un entorno serrano, la solidaridad aigüense. Pondremos en diálogo conceptos trabajados por la antropología con lo visto en nuestro trabajo de campo, pero sin perder la perspectiva histórica de cómo llegó a consolidarse la fiesta hoy en día. Finalmente, desde este trabajo invitamos a mirar este tipo de celebraciones como parte de procesos históricos donde las dimensiones ambientales, sanitarias, económicas, identitarias y culturales están en constante diálogo.
\end{abstract}

Palabras clave: Fiesta, jabalí, Identidad, Comunidad, Solidaridad

\begin{abstract}
This work seeks to know the process of identity definition of the Aiguá people (Uruguay) as an imagined community, during the Wild Boar Festival (an animal declared a national pest in Uruguay). There are several factors that operate in the construction of local identity: tradition, fighting the pest, belonging to a hilly environment where the boar inhabits, and the local solidarity. We put into dialogue the anthropological concepts of identity, community, and ritual, considering how the festival came to be consolidated as today. Finally, we invite to look at this type of celebrations as part of processes where the environmental, health, economic, identity and culture are in constant dialogue.
\end{abstract}

Key words: Party, Wild boar, identity, Community, Solidarity

\section{Resumo}

Este trabalho busca conhecer o processo de definição de identidade enquanto comunidade imaginária do município de Aiguá, Uruguai, durante a Festa do Javalí (animal declarado praga nacional em Uruguai). São vários os fatores que atuam na construção da identidade local: tradição, combate à praga, ser parte de ambiente montanhoso, e a solidariedade aigüense. Colocamos em diálogo os conceitos antropológicos de festa, identidade e ritual. Finalmente, a partir deste trabalho, propomos considerar este tipo de comemorações como parte de processos históricos onde o meio ambiente, a saúde, a economia, a identidade e a cultura estão em constante diálogo.

\footnotetext{
1 * Centro Universitario de la Región Este Universidad de la República
}

Tekoporá ${ }^{\circledR}$. Centro Universitario de la Región Este. Universidad de la República (C) di Candia y Dabezies (2020)

Este es un artículo de Acceso Abierto distribuido bajo licencia Creative Commons (CC BY NC 4.0) 
Palavras chave: Festa, javali, Identidade, Comunidade, Solidariedade.

\section{Introducción}

Este trabajo se centra en la Fiesta del Jabalí de Aiguá (Maldonado, Uruguay) también conocida como "Tradición, Jabalí y Aventura en Aiguá". Este evento se lleva a cabo el primer fin de semana de octubre desde finales de la década del 90 y a partir del 2006 es gestionada por las Instituciones Unidas de Aiguá (en adelante I.U.A), red compuesta por instituciones públicas y privadas locales tales como: Municipio, escuelas urbanas y rurales, policlínica, hogares de ancianos, clubes deportivos, sociedad criolla, comisiones de fomento y otros colectivos. La celebración se realiza durante dos jornadas consecutivas y básicamente consiste, por un lado, en una competencia de qué equipos de cazadores caza la mayor cantidad y los mejores jabalíes. En este marco competitivo la fiesta también es un evento solidario donde la comunidad de Aiguá en beneficio de la red de instituciones sociales locales y es este aspecto donde pondremos el foco.

En la zona el jabalí es considerado un animal perjudicial para la producción ovina, la cual representa una actividad económica importante. A nivel internacional y desde un punto de vista biológico y ecológico es considerado un invasor biológico. Desde la perspectiva del Estado uruguayo es considerado una plaga nacional desde 1982, según el Decreto No 463/982. Durante el trabajo de campo pudimos notar cómo el concepto de "plaga" pese a tener diferentes interpretaciones y énfasis de acuerdo con quien construye y/o reproduce el relato, tiene una potencia evidente y es reproducida en tal sentido por los organizadores del evento. La gráfica, los folletos informativos, las entrevistas en los medios, las alocuciones desde el escenario y las publicaciones en Facebook son parte y producto de esta dinámica. Es por esto que nuestro análisis requiere ver desde esta óptica local, el combate a la plaga como un factor siempre presente en la toma de decisiones por parte de la organización del evento. Y es en este marco donde analizaremos las estrategias de una pequeña población serrana para generar ingresos genuinos a las instituciones sociales. Estrategias bien específicas que se expresan mediante un proceso de cohesión sociocultural y sentimientos de pertenencia concretos que no necesariamente son compartidos de la misma manera por todos los que participan de la fiesta.

Además, nos detendremos en describir cómo está compuesta la organización de la fiesta del jabalí y más específicamente la "Coordinadora" que representa a las I.U.A. Como veremos, ésta funciona mediante reglas y procedimientos específicos estructurados con una clara división de roles y tareas, un procedimiento predefinido de elección de la jefatura del colectivo y una forma protocolizada de distribución de las ganancias.

Todos estos aspectos mencionados confluyen en la idea de una identidad propia y se manifiestan en procesos, en formas y contenidos que requieren un abordaje específico desde la antropología siendo el trabajo de campo etnográfico una herramienta imprescindible para aprehenderlos. En este artículo, desde una aproximación etnográfica analizamos el proceso de construcción de la identidad colectiva en función del combate a la plaga del jabalí. Para tal el abordaje teórico para este trabajo que desarrollaremos en el segundo apartado, se sitúa en la intersección entre los conceptos antropológicos de fiesta (Turner, 1967; de Giorgi, 2002; Homobono, 2004), identidad y comunidad (Anderson, 2000; Grimson, 2001, 2011; Silla, 2011). En nuestro análisis intentaremos problematizar estos conceptos, de contrastarlos con lo visto y relevado en el campo. 


\section{Metodología}

La investigación se realizó en base a un abordaje etnográfico, cuyo trabajo de campo se llevó a cabo durante los años 2006, 2007, 2016 y 2017. En el mismo se utilizaron técnicas tradicionales de la antropología tales como: entrevista abierta y semiestructurada, observación directa y participante, charlas informales, diario de campo, registro fotográfico y audiovisual, relevamiento de prensa y redes sociales. Un aspecto fundamental del abordaje etnográfico reside en la posibilidad de acceder multi sensorialmente a la información y así comprender los aspectos más subjetivos y fenomenológicos de la experiencia festiva, donde la observación participante de esta actividad implica y exige estar informado sobre la actividad y practicarla. El dato etnográfico fue construido mediante un proceso analítico antes, durante y después del trabajo de campo en Aiguá e implicó un diálogo permanente entre los participantes y una continua categorización, recategorización y segmentación de los datos (Hammersley y Atkinson, 2001).

Fueron muchos y diversos los informantes (organizadores, cazadores, feriantes, actores estatales, público en general) para este trabajo y en su gran mayoría explicitaban un relato similar sobre la celebración. En el mismo destacaban su carácter benefactor, su organización comunitaria y el objetivo que de alguna manera "cohesionaba a sus habitantes", por un lado, lograr beneficios económicos para la red institucional local, y, por otro lado, la necesidad de dar muerte a una plaga que los amenaza como comunidad: el jabalí.

\section{Aiguá y el jabalí}

Aiguá se encuentra ubicada a 88 kilómetros de la ciudad de Maldonado y a 50 kilómetros de la ciudad de Minas, en la región este del Uruguay. En base a datos del censo nacional del 2011, el municipio cuenta con una población de 3.165 habitantes. Las actividades económicas principales son: producción ganadera (principalmente ovinos y vacunos), producción de granos (soja, sorgo, maíz), servicios (comerciales, públicos) y el turismo vinculado a la sierra . Aiguá está situado en una de las zonas más serranas del territorio nacional. Al sur, las sierras de Carapé; al oeste, el arroyo Aiguá marca el límite con el departamento de Lavalleja y al este, la separa de Rocha el arroyo Alférez. En 1906 se reconoció oficialmente a Aiguá como pueblo, dándosele en 1956 la categoría de ciudad y de Municipio en el 2010. A su vez en la zona de influencia municipal de Aiguá está ubicado el punto más alto de Uruguay con 513 metros de altitud. El paisaje agreste de la zona es muy particular por la variedad de formas y tonalidades. Está dominado por sierras y cerros donde predominan diversas formaciones rocosas que recortan sus grises perfiles por encima del ruedo verde del bosque nativo que cubre sus bases. En sus profundas quebradas se encuentra, además de la diversa y abundante cantidad de fauna nativa, el nuevo vecino: el jabalí europeo.

El jabalí o Sus scrofa es un mamífero de la familia de los suidos (Suidae). De tamaño medio es un animal que pesa, los machos adultos, entre 60 y $120 \mathrm{Kg}$ (jabalíes puros), con hocico relativamente corto, patas cortas, gran cabeza, morro largo y prácticamente sin cuello. Esto le da un aspecto macizo y compacto. En promedio alcanza una altura a la cruz de $1 \mathrm{~m}$, siendo más largo que alto. La cabeza cónica se extiende en un hocico que termina en un disco duro y móvil donde están los orificios nasales. El tamaño varía de acuerdo según el ambiente y alimento disponible (Lombardi, Geymonat y Berrini, 2015). Originario de Eurasia, es el ungulado que tiene el rango natural de dispersión más amplio y actualmente está presente en todo el mundo. Esta gran dispersión se debe a su gran adaptabilidad ecológica y su milenaria relación con el ser humano a través de la domesticación. El jabalí ha sido un animal de caza mayor muy popular 
en la historia de occidente. De hecho, estuvo extinto en países como Gran Bretaña o Suecia, pero luego, a lo largo del siglo XX, debido a la enorme expansión de la especie por la reintroducción o la liberación de cerdos domésticos, ha crecido enormemente transformándose en un codiciado objeto de caza (Yamamoto, 2017).

Pero llegados a este punto nos preguntamos, ¿qué otros factores, además de los perjuicios económicos, inciden en la práctica tradicional de cazar al jabalí? El término jabalí en portugués y castellano, proviene del árabe djabali que significa montaraz, describiéndolo como un cerdo de monte, que vive en los márgenes de las zonas productivas donde están los animales domesticados (Sordi, 2017). Los jabalíes son animales especialmente aptos para defenderse de predadores naturales, comportamiento fundamental de su feralidad. Al respecto C. Sordi propone la idea de la feralidad como un "operador conceptual" interesante para superar la lógica binaria de naturaleza/cultura o doméstico/salvaje. Este autor señala que:

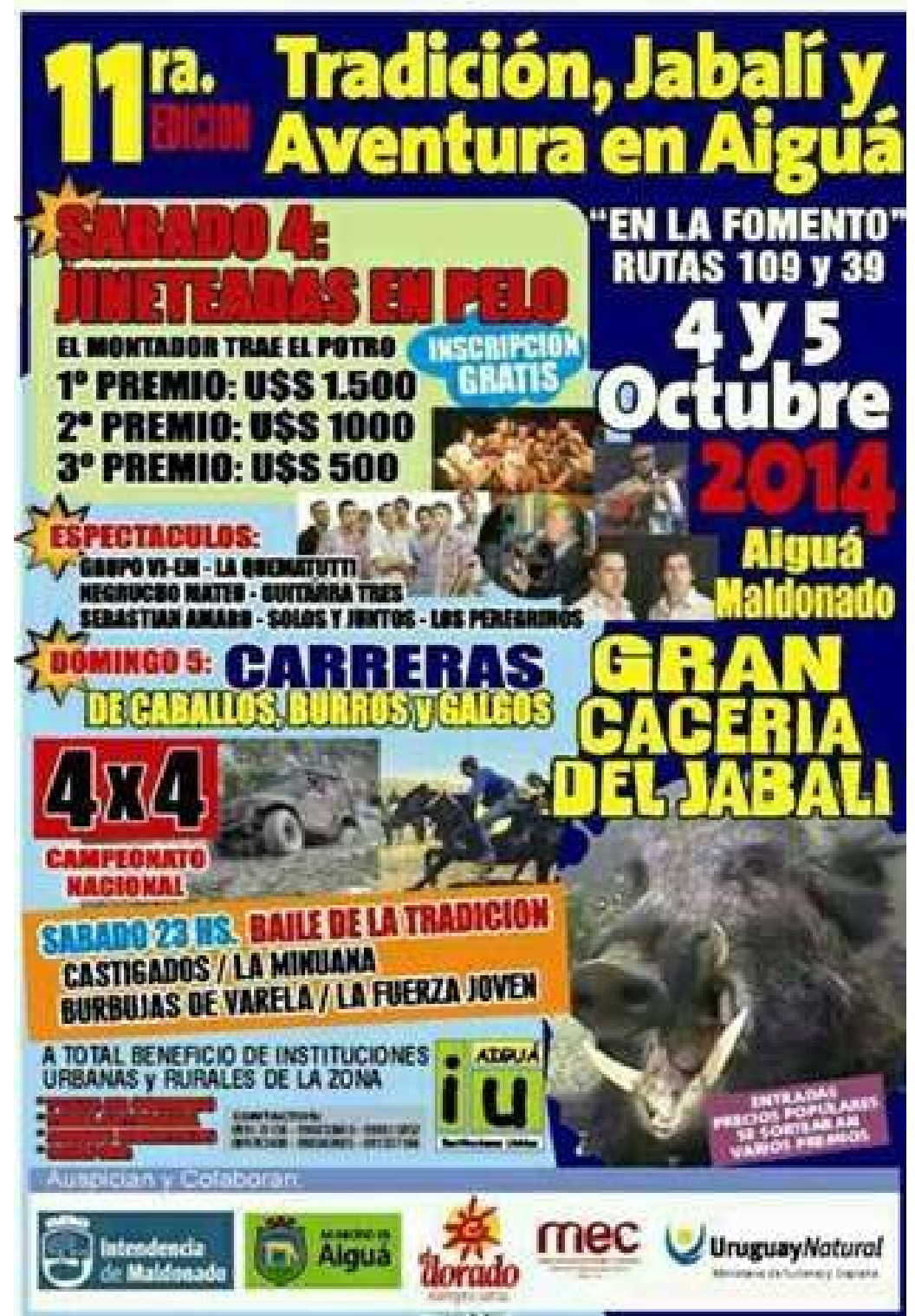

"o feral não é o oposto do doméstico - papel este exercido pelo selvagem -, mas o indício de suas fissuras e contradições. Assim, mais do que qualquer coisa, o feral é o modo com o qual o selvagem habita a domesticidade desde dentro, e não o encontro ou a hibridização entre dois domínios distintos. Formulando de outra maneira, se o híbrido é uma intersecção entre conjuntos (natureza/cultura, selvagem/doméstico, etc.), o feral é o elemento que faz de todo conjunto ou regime de domesticidade uma totalização inconsistente, uma estrutura necessariamente vazada e porosa, permeada por múltiplas linhas de fuga." (Sordi, 2017, p. 288).

Esta feralidad del jabalí es constantemente resaltada en las fiestas. Esto se puede ver, por ejemplo, en los afiches de difusión diseñados por los organizadores de la fiesta, donde se utilizan imágenes de jabalíes destacándose sus características ferales y amenazantes (Figura 1).

Figura 01. Afiche de difusión de la Fiesta del Jabalí e Aiguá en el año 2014. Afiche en formato digital elaborado por la Coordinadora de la fiesta y remitido a los autores. 


\section{Fiesta, identidad y comunidad imaginada.}

Existe una amplia tradición, ya desde sus orígenes, en cuanto a estudios de rituales, fiestas y cultura popular en antropología. Durante décadas las ciencias sociales y la antropología abordaron de manera separada esta cuestión poniendo el foco fundamentalmente en la religión o la función social de los rituales. Homobono (2004) realiza un extenso repaso de este tema, atribuyendo un lugar importante a los trabajos realizados por Durkheim (1912), Radcliffe-Brown (1952), Leach (1954), Turner (1967), entre otros. En la región rioplatense, los trabajos de Oliven (1999), Da Mata (1997), Silla (2011) y de Giorgi (2002), entre otros, han sido hitos importantes en este tema. Este trabajo se inscribe dentro de esta tradición del estudio antropológico de las fiestas, considerándose como un momento en el cual se expresan y potencian sentimientos de pertenencia, proceso que, en muchas ocasiones, termina por redefinir a los grupos sociales (Homobono, 2004).

En este trabajo consideramos a la fiesta como:

"una celebración cíclica y repetitiva, de expresión ritual y vehículo simbólico, que contribuye a significar el tiempo (calendario) y a demarcar el espacio. Se sitúa en oposición al tiempo ordinario y a la vida cotidiana, y establece una relación dialéctica, paradójica y contradictoria, entre lo sagrado y lo profano, la ceremonia -religiosa o cívica- y lo lúdico, la celebración y la rutina, las pautas de institucionalización y de espontaneidad, la liturgia y la inversión, la trasgresión y el orden, la estructura y la communitas, las dimensiones de lo público y de lo individual." (Homobono, 2004, p. 34).

En este sentido uno de los objetivos de las fiestas es el de cohesionar a los individuos y grupos; las celebraciones generan y reactualizan sentimientos de pertenencia a un pueblo o territorio. La fiesta aporta significativamente a la (re)construcción colectiva de la memoria(s) e identidad(es) local(es); de experimentar una comunidad imaginada mediante la actuación concreta de grupos o personas como agentes del ritual festivo.

Siguiendo a de Giorgi (2002), a la hora de describir la "Fiesta del Jabalí" partimos desde su "multidimensionalidad", manifiesta en las múltiples actividades que bajo su invocación se realizan. En su trabajo sobre "La Fiesta de la Patria Gaúcha" de Uruguay, De Giorgi señala que esa fiesta es un espacio "de competencia deportiva; de control de la cultura popular, de plataforma política local, últimamente de expansión del capital y es también la confusa suma de todos ellos" (de Giorgi, 2002, p. 36). Desde esta perspectiva encontramos coincidencias con la Fiesta del Jabalí, ya que es una situación donde también se activan y reactualizan símbolos comunes vinculados a la tradición, principalmente gauchescos y criollos; un espacio de entretenimiento y de encuentro; un momento específico dentro del calendario donde cazar jabalíes tiene "sentido"; una oportunidad para revalorizar elementos de la vida serrana; y también, un espacio donde se disputan y negocian poderes entre los niveles de gobierno: vecinal, municipal y departamental.

También nos resulta fundamental para este trabajo la noción de ritual, ya fuertemente trabajada por la tradición antropológica, para dar cuenta de las prácticas y símbolos que allí están en juego. En este sentido, el/los escenarios/s, el reglamento, la disposición y roles de los actores, los símbolos, vestimentas, sonoridades entre otros objetos y hechos, sirven para el análisis de este ritual. En palabras de Turner (1967) sería una conducta formal prescrita en ocasiones no dominadas por la rutina tecnológica, y relacionada con la creencia en seres o fuerzas místicas. De esta manera el símbolo sería, según Turner, la más pequeña unidad del ritual que todavía conserva las propiedades específicas de la conducta ritual. Y por símbolo entiende que es una cosa de la que, por general consenso, se piensa que tipifica naturalmente o representa, o recuerda algo, ya sea por la posesión de cualidades análogas, ya por asociación de 
hecho o de pensamiento. Los símbolos que observamos sobre el terreno eran empíricamente objetos, actividades, relaciones, acontecimientos, gestos y unidades espaciales en un contexto ritual (Turner, 1967).

Estos símbolos están estrechamente vinculados con los procesos de definición de las diferentes identidades durante la fiesta. Pero también acordamos con Grimson (2001) cuando plantea que, dentro de la cultura, no sólo hay diversidad o heterogeneidad, sino una lógica instituida de interrelación entre las partes, que implica una noción clara sobre su significado. Las personas que habitan una cultura y no comparten uno u otro rasgo frecuente a su alrededor, significan distintamente ese rasgo y esa diferencia que alguien que habita otra cultura. Si bien existen estas fronteras culturales, las culturas no pueden ser consideradas como sumatorias diferentes de rasgos, más bien serían producto de combinatorias distintas, articulaciones específicas, estructuras contingentes e históricas de elementos que adquieren significado en la trama de relaciones entre estos. Grimson (2001) también propone pensar a la cultura como configuración, ya que está conformada por innumerables elementos de diferente tipo que guardan entre sí relaciones de jerarquía, oposición, y complementariedad. Con relación a esto define la identidad como un sentimiento de pertenencia asociado a una categoría, siendo a su vez un elemento clave de una cultura.

En referencia a las diversas categorías de auto adscripción identitaria Silla (2011) plantea en su trabajo Colonizar argentinizando: Identidad, fiesta y nación en el Alto Neuquén, que lo que allí se percibe no es un pasaje hacia otra categoría ya establecida o la aparición de una nueva, sino la superposición de categorías ya existentes: la de argentino, la de chileno, la de indio. En nuestra investigación pudimos notar, problematizándolo desde una escala local y no nacional como Silla, que también existe este tipo de superposición de categorías. Pero al mismo tiempo existe un sentimiento de identidad común que se fortalece frente a la necesidad de lograr recursos económicos genuinos mediante una gestión colectiva y reglamentada del evento.

En este sentido también es muy útil la noción de comunidad imaginada de Benedict Anderson (2000) siguiendo la premisa de mirar estas cuestiones en una escala local. Según el autor la nación puede ser definida como una comunidad política imaginada como inherentemente limitada y soberana. Es imaginada, explica, porque los miembros de esa comunidad no podrán conocer nunca a todos sus compatriotas, pese a lo cual "en la mente de cada uno vive la imagen de su comunión" (Anderson, 2000). En este caso, la comunidad se imagina no tanto por el desconocimiento de sus integrantes sino, en primer lugar, por el sentimiento de amenaza permanente del jabalí en tanto plaga y sus consecuencias; y en segundo lugar por la necesidad de reforzar los lazos entre vecinos de Aiguá.

En Aiguá el "problema del jabalí" y la necesidad de obtener fondos por parte de las instituciones locales se fueron articulando a lo largo de los años dándole formas, estrategias, modos de gestión, contenidos, signos, símbolos, discursos y prácticas que fueron solidificando una fiesta bien específica. Para quienes organizan, participan y/o solamente disfrutan de La Fiesta del Jabalí, a partir de su ritualidad y simbolismo, donde se configura esa realidad colectiva, lo simbólico da sentido también a lo económico, social y político. Se refuerza la idea de que hay que combatir al jabalí porque causa daños económicos a la producción agropecuaria; se manifiestan y activan redes institucionales, de colectivos sociales; se activan y expresan liderazgos políticos de diversa índole. Es decir, lo que sucede, pero sobre todo los significados de lo que sucede, el cómo, el marco de lo que sucede tiene sentidos bien específicos compartido por quienes participan. Como veremos a continuación, un ejemplo de esta diversidad de interpretaciones y sentidos es el que se refiere al origen de la fiesta. 


\section{Resultados}

La fiesta del jabalí y sus dos nacimientos

No hay un relato oficial común sobre la fecha de origen de la Fiesta del Jabalí. Según pudimos relevar con distintos informantes, esta surge a finales de la década de 1990 a iniciativas de un referente político, empresario y cazador de la zona, conocido localmente como el señor Bentancur. Luego de cambiar de locación dos veces terminó recalando en su lugar actual, el predio de La Sociedad de Fomento Rural de Aiguá (conocida localmente como "La Fomento"), ubicado en la intersección de las rutas nacionales 39 y 109. Como se puede ver en el siguiente testimonio, este es el relato más extendido entre los cazadores:

"Hace muchos años (de) la tradición, hace unos cuantos años se hace la tradición del jabalí, no recuerdo, pero debe ser 25 o 27 años, no recuerdo bien que año (...). Cuando apareció, como yo fui criado entre la sierra, aparecieron los primeros chanchos debe hacer unos 30 años más o menos. Y bueno, una vuelta Bentancur inventó una cacería y bueno salimos, nos invitaron y salimos siete equipos en aquel momento. Nosotros, un lote de compañeros que trabajamos en la intendencia y teníamos perros y vehículos para salir. Para nosotros es un orgullo, ser de Aiguá y andar batallando. Los primeros puestos que ganamos fueron como un lujito." (Diario de campo, extracto de diálogo con Enrique, 7/10/2017).

Sin embargo, la Fiesta del Jabalí parece tener dos nacimientos y según el actor con el que se conversa, pone el acento en uno u otro origen. Para muchos integrantes de la organización, y cuanta menos cercanía tenga ese actor con la caza más se evidencia, la fiesta comienza en el año 2005 cuando las instituciones de Aiguá se nuclearon en una red y, sumado al apoyo político de la Junta Local, tomaron el control y la gestión de la fiesta. Luego de darse cierta disputa por el control de la gestión, la distribución de las ganancias y beneficios quedó en manos de las Instituciones Unidas de Aiguá (aspecto que profundizaremos más adelante). También a partir del 2006 comenzó a llamarse Tradición Aventura y Jabalí en Aiguá, aunque popularmente se la sigue llamando hasta el día de hoy La Fiesta del Jabalí. En definitiva, la Fiesta pasó de ser gestionada y dirigida por un privado a ser gestionada por una red de instituciones locales con fuerte apoyo municipal. Esto es confirmado por los integrantes de las I.U.A:

"Es la edición número catorce estoy casi segura, que es desde que la organizan las instituciones, pero antes era como a través de la intendencia, el señor Bentancur organizaba todo y algunas instituciones se beneficiaban con las entradas, un mínimo porcentaje de las entradas (...) Nos hemos beneficiado en cómo se organiza ahora. Antes la organizaba una persona. Si bien como nosotros como institución me tocó participar no como coordinadora del centro juvenil sino como maestra de una escuela. Venias cobrabas las entradas y te daban solo un porcentaje de esas entradas que era mínimo. Ahora repartimos en partes iguales y ahora las instituciones se ven más beneficiadas." (Diario de campo, extracto de diálogo con Silvia, 1/10/2016).

A pesar de que todos los años hay pequeñas modificaciones en la propuesta artística o se agregan o quitan actividades, la estructura de la fiesta, lo que sucede y en el orden en que sucede es prácticamente el mismo. En síntesis, la estructura básica sería:

- Sábado. En la mañana es el comienzo de la fiesta, donde se da el registro de los cazadores, la apertura de los puestos de comida y la feria y comienzan las actividades ecuestres (jineteadas, pruebas de rienda) que siguen durante la tarde. En la noche hay pruebas artísticas y cierre con un gran baile.

- Domingo. En la mañana se desarrolla el concurso y pruebas de fuerza de 
camionetas $4 \mathrm{X} 4$ y continúan las pruebas ecuestres. De tarde se da el momento más importante de la fiesta con la llegada de los cazadores a partir del mediodía y posterior presentación de las piezas y actuación del jurado y entrega de premios. Finalmente, el evento cierra con espectáculos artísticos.

Son muchos y muy diversos los actores de la fiesta y estos se interrelacionan entre sí en una compleja trama donde el grado y estatus en la misma está atravesado por temas como el género, la identidad o el tipo de pertenencia institucional. Los testimonios de la comisión organizadora, así como las diversas gacetillas de prensa y redes sociales afirman que año a año se acercan al predio de La Fomento un promedio de cinco mil personas por fin de semana , aunque nos han afirmado que llegaron a superar las cinco mil personas en más de una edición.

El público que asiste se podría dividir en familias de la localidad de Aiguá y de otras localidades vecinas (fundamentalmente San Carlos, Maldonado, Minas, Rocha, Varela, Mariscala y Treinta y Tres), cazadores de la zona y sus familias, cazadores regionales y de otras partes del territorio nacional, vendedores privados en puestos de feria y otros servicios y en menor medida otros visitantes ocasionales. Durante los días de festejo el público elige qué propuestas acompañar lo que hace que sea más que nada intermitente y vaya fluctuando su cantidad y concentración en el predio de La Fomento. Por ejemplo, el sábado de mañana al comenzar la fiesta es común ver un público más familiar paseando por el predio, principalmente por la feria de productos artesanales y artículos de campo, entre otros. A medida que avanzan las horas y principalmente en las actividades centrales como el concurso de jineteadas, el baile de la noche y principalmente la llegada de los cazadores el domingo, es cuando se ve la mayor cantidad de gente. Pero en ese momento cambia el perfil de los asistentes a la fiesta. Si bien es notorio el perfil familiar durante el día y juvenil durante la noche, quienes se identifican con la actividad cinegética concentran su asistencia el domingo por la tarde, con la llegada de los cazadores.

Recorriendo la Fiesta del Jabalí

El sábado temprano se abren las porteras de La Fomento. En la boletería dos mujeres con camisetas que dicen "organización”, cobran las entradas mientras dan indicaciones a los cazadores que preguntan desde las camionetas “¿En dónde se inscriben los equipos de cacería?".

Desde que la fiesta se terminó de consolidar como se conoce actualmente, participan en promedio unos doscientos cincuenta cazadores. Los equipos son conformados en promedio por cuatro o cinco integrantes, aunque hay algunos que superan los diez. Están compuestos por hombres entre los dieciocho y los sesenta años y, al menos en las instancias en las que fuimos a las fiestas, no se vio la presencia de mujeres.

A media mañana el público va eligiendo donde sentarse para comprar su porción de asado con cuero o de tira de vaca, unos chorizos caseros de cerdo, pollos o buseca, todas comidas típicas que suelen consumirse en las fiestas criollas. La oferta gastronómica es una de las diferentes fuentes de recaudación junto con las rifas y las entradas al predio a precios accesibles (entre 2 y 3 dólares). En su gran mayoría se ven mujeres de todas las edades atendiendo los puestos de venta con excepción del bar y las parrillas que son atendidas por hombres exclusivamente.

Al mediodía comienzan las pruebas ecuestres, en este caso pruebas de rienda (concurso de montas, en pelo y basto). Mientras, las familias y público en general pasean por la feria de artesanías donde se venden productos locales artesanales, vestimenta e insumos vinculados al campo, entre otros. De fondo suenan canciones de pop latino, cumbias, música popularfolclóricas (polkas, serraneras, zambas y chacareras, y en menor medida candombe y murga) y entre canción y canción el locutor que anima a las familias a acercarse al ruedo, indica donde 
están los juegos infantiles o invita a "disfrutar de las delicias camperas y criollas" como el asado con cuero y los chorizos caseros de cerdo y de vaca.

Al recorrer el predio uno va acompañado de la voz de locutor que nos recuerda en todo momento uno de los principales objetivos de la fiesta: ayudarnos entre todos por y para la comunidad de Aiguá. Es quien lleva el guión y al mismo tiempo maneja los climas en las diversas situaciones que se viven. Es también quien destaca los valores de la celebración, como, por ejemplo, la colaboración con las instituciones del pueblo, ayudar a la escuela Nro. 6 a recuperar el cerco perimetral, o a la escuelita de fútbol a comprar camisetas o al destacamento de bomberos de la zona. Promueve a las familias a comprar las rifas o tiques para poder apoyar a la comunidad aigüense y de paso "degustar un auténtico asado con cuero o buseca criolla".

Tanto el sábado como el domingo de mañana se ve el trabajo coordinado de los integrantes de las instituciones que llevan adelante el evento. Luego, en las horas donde se da el pico de público (por ejemplo, al finalizar las competencias ecuestres al mediodía, o a la noche durante la actuación de algún artista popular, o en la llegada de los cazadores el domingo) es más difícil verlos y entrevistarlos, se los ve muy atareados y prefieren no ser entrevistados. Pero están ahí y se los ve trabajar, funcionan de manera organizada con delegados y responsables por áreas, tienen horarios específicos, procedimientos establecidos por reglamento . Llevan camisetas identificatorias, son un grupo coordinado que trabaja en beneficio de la comunidad. Este colectivo está compuesto por un promedio de doscientas personas (directa e indirectamente), en mayor cantidad mujeres, aunque este número varía según la cantidad de instituciones que se involucran cada año. También hay que mencionar a los diversos actores estatales que participan en la fiesta desde otros lugares. Este grupo no es tan uniforme como el de los cazadores y se compone por representantes de varios organismos que, ya sea territorial o eventualmente, cumplen con alguna función en el evento (funcionarios y jerarquías municipales, funcionarios y jerarcas de la Intendencia de Maldonado, algunos integrando alguna de las comisiones de gestión, funcionarios policiales, técnicos del Ministerio de Ganadería Agricultura y Pesca -en adelante MGAP- o el Ministerio de Turismo -en adelante Mintur-, entre otros). De hecho, es común que se realicen conferencias de prensa en conjunto con los diversos actores institucionales involucrados en el evento semanas antes de la celebración.

Otro grupo que es interesante resaltar es el de los artesanos y vendedores de productos locales. Varios de los vendedores son habitantes de la localidad y de las zonas más rurales de la sierra de Aiguá. A pesar de no ser el centro de esta investigación, se percibe una interesante oferta de productos vinculados a la identidad local serrana, objetos y equipamientos tradicionales criollos (talabartería, hojalatería, talla en madera, pirograbados, cultura ecuestre, otros), objetos y equipamientos vinculados a la caza (ropa con estampados militares, botas, gorras, etc.) y también productos artesanales asociados a lo orgánico y agroecológicos (mermeladas, mieles, cremas curativas, hierbas aromáticas, entre otros). Este grupo heterogéneo, un aproximado de 50 personas, está compuesto por vecinos locales, de los alrededores y en menor medida feriantes de productos textiles o de origen chino de la zona.

El entramado que se da en las fiestas, donde se activan interpretaciones, miradas, conflictos y negociaciones, termina moldeando una forma de organización propia. Las maneras en que se organizan gestionan y ejecutan las fiestas van cambiando según variables históricas, sociales y económicas, por nombrar algunas. Es así como luego de transitar por muchos cambios se llegó a la organización actual donde se articulan las decisiones entre el gobierno departamental y municipal con la coordinadora de la fiesta que representa a las I.U.A. A continuación, conoceremos más en profundidad cómo se estructura y reglamenta dicha coordinadora. 


\section{Instituciones Unidas de Aiguá}

Como se mencionó previamente, la fiesta está organizada y gestionada por las instituciones y colectivos públicos y privados de la localidad. Estos no necesariamente tienen vínculos entre sí durante el resto del año a menos que sean convocados para la organización y gestión de más eventos benéficos, espacio en el que vuelven a encontrarse. El territorio cubierto por los grupos no está delimitado geográficamente, su extensión se da a través de los servicios que prestan a la ciudadanía tanto en el casco urbano como en el área rural de Aiguá. También cabe destacar que las I.U.A están conformadas por instituciones tanto públicas como privadas y que al menos dos niveles de gobierno están allí representados (sociedad civil y Municipio). Tampoco es una temática específica la que las aglutina como puede ser el desarrollo social, la cultura o lo económico comercial. El principal motivo es la alianza para diseñar, gestionar la Fiesta del Jabalí para luego redistribuir sus ganancias.

Esta red de instituciones se autoconvoca a comienzos de mayo, cuentan con un reglamento que organiza su participación y la posterior gestión de la fiesta. Según este reglamento, el principal objetivo es el de recaudar fondos en beneficio de estas instituciones y por ende beneficiar a toda la localidad. La cantidad de instituciones involucradas cada año en la fiesta varía de acuerdo con la coyuntura del momento y/o la capacidad de hacerse cargo de las responsabilidades asumidas. Al respecto, las tareas definidas son: la faena de la carne y producción de chorizos una semana antes, venta de rifas, limpieza, atención de puestos de comida preelaborada, venta de entradas y tiques, atención de las parrillas, venta de buseca, atención del bar, apoyo logístico y de organización en el ruedo y competencias de camionetas 4X4, coordinación de la cacería, difusión y comunicación, tareas de administración y contabilidad general, voluntariado para otras tareas que surjan.

Las aproximadamente treinta instituciones que integran I.U.A año a año deciden si participar o no en la fiesta de acuerdo con sus necesidades financieras y capacidad de participación en La Coordinadora. En promedio son unas veinte que trabajan activamente en la organización y gestión de la Fiesta cada año en la organización. La Coordinadora está compuesta por diez delegados representantes de cada institución que integra las I.U.A (unas trescientas personas en promedio). Estos delegados eligen una Directiva donde se centralizan las decisiones, ajustan y rediseñan en cada edición que es lo que va a suceder, de qué manera y quienes lo van a hacer. Las tomas de decisión se hacen por votación en la Asamblea en base a mayoría simple y si surge algún tema de compleja resolución, se convoca al resto de las Instituciones para tratarlo y decidir en conjunto.

Como mencionamos antes, cuentan con un reglamento que fue elaborado en el año 2009 y sintetiza los acuerdos producto de muchas reuniones de coordinación entre las I.U.A. Desde el punto de vista de Anderson (2000) se podría considerar a este reglamento como estructurador del sentimiento de comunidad y a la fiesta como cohesionador de una comunidad política en pos del beneficio de la red institucional, estableciendo un órgano representativo de toma de decisiones. Para este autor la comunidad política se imagina como inherentemente limitada y soberana. Esto quedaría reflejado en las definiciones y funciones de la asamblea:

"La asamblea es el órgano principal y soberano, que regirá las acciones necesarias para la realización de los eventos. La cual estará compuesta por un representante de cada institución debidamente inscripta y el número de integrantes será el producido de las inscripciones realizadas, y que se registren en tiempo y forma" (Extracto del Reglamento de Funcionamiento en la Realización de Eventos, de Instituciones de Aiguá, 3 de julio de 2009) 
En este caso los límites de esa comunidad política, o sea quién está adentro o afuera, no están determinados por fronteras o distancias geográficas sino por un simple acto voluntario y explícito de querer participar de la misma. Andrés, que es parte de la Coordinadora desde hace varios períodos, nos dice que "Nosotros damos prioridad a todas las instituciones, está en ellas participar o no. Hacemos un llamado en mayo a aquellas instituciones que quieren participar en el evento jabalí, tanto puede subir una institución como puede bajar" (Diario de campo, extracto de diálogo, 7/10/2017).

Analizando el reglamento y los testimonios de los organizadores como Andrés, queda claro cómo se da la pertenencia al colectivo que organiza la fiesta. Aquí el énfasis está puesto, primero, en un acto voluntario de la institución de querer pertenecer o no a cada edición del evento y, segundo, en la asunción y sentimiento explícito de pertenecer a la Coordinadora. Como mencionara Grimson (2011) la identificación es siempre una definición de los actores sociales y no una conclusión objetivista del investigador. También se manifiesta con claridad en las charlas a la hora de presentarse las diversas identidades individuales a manera de capas:

"Soy Patricia, directora de la escuela rural y soy parte de la Coordinadora; o, me llamo Sergio, soy tropillero, soy agricultor, soy capataz de campo de las jineteadas, y soy delegado de la Coordinadora por la Sociedad Criolla Marcheros de Aiguá; mi nombre es Carlos, vengo en representación de la Intendencia de Maldonado y soy integrante de la Coordinadora" (Diario de campo, extracto de diálogo, 2016 y 2017)

Estas adscripciones o identidades superpuestas en términos de Silla (2011) surgen y se explicitan según el tema que se converse y los intereses en juego. Por ejemplo, cuando surge el tema del jabalí como una amenaza o plaga los actores dejan de lado su pertenencia a La Coordinadora y narran alguna situación o anécdota que los vincula con el jabalí y sus perjuicios. Por ejemplo, Patricia que es maestra rural nos dice:

"Si hablas con la gente de la zona, con los padres de los alumnos y tienen problema, viste que crían ovejas y tienen problemas, les matan los corderos, y si plantan les comen todo, si plantan maíz y sorgo les comen todo. Un año plantamos maíz en una parte en la chacra y venían todas las noches a comerse el maíz (...) Nosotros les enseñamos (a los alumnos) siempre que hay pesar de que es una plaga, les enseñamos a respetar los animales, pero lo que pasa es que ellos viven esa realidad que les afecta en la casa y los ven como una plaga." (Diario de campo, extracto de diálogo, 7/10/2017).

En referencia a las diversas categorías de auto adscripción, en su trabajo en Neuquén, Silla (2011) plantea que lo que allí se percibe, no es un pasaje hacia otra categoría ya establecida o la aparición de una nueva, sino la superposición de categorías ya existentes. En este sentido, la generación y mantenimiento de la identidad no estaría presentada como una dicotomía y que, por el contrario, esas identidades aparecen borrosas, permeables y ambiguas (Silla, 2011). Esta característica, la de asumir y explicitar diversas identidades de acuerdo con el tema de conversación, se vio más presente en los integrantes de la comisión organizadora, quienes integran La Coordinadora y no tanto con los cazadores, para estos su condición de cazador estaba más consolidada, más firme frente a un "enemigo" que hay que combatir.

\section{Identidad y comunidad en la fiesta}

No parecen existir muchas discrepancias en cuanto al carácter fuertemente identitario de la fiesta. El repertorio simbólico que se dispone desde la organización de la Fiesta del Jabalí refiere a elementos que son percibidos como propios (lo serrano, lo gauchesco, la solidaridad de la comunidad, entre otros). Esto es fácil de percibir durante los días de la fiesta y además se confirma en las entrevistas a vecinos de la localidad durante la celebración, entrevistas a 
miembros del comité organizador, relevamiento de pautas radiales y gráfica relevados y analizados entre 2006 y 2017.

Siguiendo con Grimson (2011), los conceptos de cultura e identidad aluden a aspectos analíticamente diferenciables de los procesos sociales, y la relación entre ambos no se puede entonces presuponer ni generalizarse. Es por esto fundamental analizarlos por separado, así como asumir que las respuestas sólo se encuentran en cada caso empírico. Siguiendo esta premisa pudimos constatar que durante los días de fiesta en Aiguá se viven y expresan dentro de un marco cultural común, pero a la interna existen clasificaciones y divisiones significativas. Los sentimientos de pertenencia con la cultura del grupo no necesariamente van de la mano. A la hora de ponderar la relevancia de la fiesta, los participantes también ponen diferentes énfasis.

Sergio es integrante de La Coordinadora, encargado del ruedo y las pruebas ecuestres. Según él,

"El ruedo de acá de La Fomento es uno de los mejores ruedos que hay en el mundo por decir en todo el Uruguay por las comodidades que hay y la gente de acá es toda gente gaucha, tradicionalista. Siempre hay gente que le gusta subir a un caballo. Somos gente de raza de gente que le gusta el caballo. Si si, es una cosa de nosotros, la tradición. Si si, ya está la fecha...octubre y mayo ya está como tradición, tradición de jabalí y aventura. La gente está como esperando que llegue la fecha para hacer, nos acostumbramos a la fecha si". (Diario de campo, extracto de diálogo, 6/10/2017). Jabalí:

Víctor es cazador y uno de los responsables del concurso de caza, y para él la Fiesta del "es una fiesta reconocida a nivel nacional. La fiesta del Jabalí, la cacería del jabalí es nacida en Aiguá, es acá. Después la han hecho en todo el país, pero la fiesta del jabalí es acá...es una tradición en la zona...incluso esta fecha de octubre de la fiesta del jabalí es una fiesta nacional que ya está inscripta en todas las fechas nacionales de eventos. Octubre la fiesta del jabalí en Aiguá ya está (...). Tiene el número 14 pero viene de mucho antes. Esta debe ser la forma 14 años que la realizan las instituciones, pero viene de mucho antes." (Diario de campo, extracto de diálogo, 6/10/2017).

La Coordinadora, mediante su reglamento, intenta fomentar una identidad propia, valores, un relato en cuanto a su "nacimiento", un órgano soberano de toma de decisiones, un procedimiento de ingreso al grupo, fines en común, mecanismos de control y sanción de faltas. Paola es maestra rural y atiende el puesto de comidas donde se venden tartas, pizzas y alfajores. Mientras estira la masa de las tortas fritas nos cuenta que esta fiesta es importante porque "es una forma de reunir gente, de que las instituciones puedan reunirse y trabajar juntas por un mismo fin económico. Pero además es una fiesta que ha ido perdurado por los años y no hay otra fiesta como esta en la zona" (Diario de campo, extracto de diálogo, 1/10/2016).

Una delegada por el Centro Juvenil de la zona da su opinión sobre la organización de la fiesta y expresa un denominador común con todos los diálogos que mantuvimos en las diferentes instancias en Aiguá:

"Nosotros en realidad, si bien lo económico prima también porque es una manera de obtener ganancias, también prima la integración con otras instituciones porque en estos días todos nos vemos, nos reunimos, trabajamos a la par con el mismo fin. Eso es fundamental, más en una localidad pequeña como es Aiguá, fundamental para nosotros como equipo integrarse a otras personas, y para los jóvenes también que vean un poco eso. Enseñarles que uno debe 
aprender a trabajar en equipo con otras personas. Porque estamos un poco alejado s de todo y es la instancia que tenemos de reencuentro...Trabajo en comunidad donde unos ayudan a otro. Es fundamental. Es una de las cosas que más nos motivó aparte de lo económico. Y te insisto en esta parte de estar todos juntos en esta instancia de compartir, es diferente, nos ayudó a integrarnos más, a trabajar como en redes todos juntos". (Diario de campo, extracto de diálogo, 7/10/2017).

Estos testimonios se repiten continuamente: el carácter benefactor de la fiesta, la unión entre vecinos, y principalmente la redistribución equitativa de los ingresos. Pero también la posibilidad de trabajar en equipo, de comunidad trabajando unida para un fin común: la propia comunidad pese a pertenecer a diferentes colectivos.

Pasados treinta días de cada evento se realiza la reunión de Devolución y Distribución de los fondos obtenidos. Es un momento de mucha relevancia para quienes trabajaron por las I.U.A, el mismo se realiza en alguno de los clubes sociales y deportivos de Aiguá, es dirigido por la Coordinadora, supervisado por un escribano público, y donde también llevan registro los medios de comunicación locales y a veces de la región. En el mismo se siguen los lineamientos del reglamento y además se recuerdan y explicitan los objetivos y valores de la comunidad política de Aiguá representada en las Instituciones Unidas de Aiguá. Durante toda la ceremonia se destaca el trabajo conjunto, la unión entre las instituciones, el trabajo sacrificado, la responsabilidad en la tarea asumida, la colaboración de los vecinos participando de la fiesta, y por supuesto la redistribución de las ganancias de manera equitativa. Muchos integrantes institucionales que participan en la gestión de la fiesta le llaman "devolución" a esta actividad, término que analizamos en un doble sentido: la devolución del trabajo invertido (horas de trabajo, compras de rifas, etc.), en dinero para las instituciones, por un lado, y por otro, la devolución desde la estructura que dirige las I.U.A de cómo realizaron dicho trabajo. Carla nos dice que:

"La devolución de como estuvo o como trabajo cada equipo de trabajo...Cuando a vos te toca por ejemplo con la cazuela, tienes que organizarte y traer todo para trabajar. Ese tipo de cosas, cuando fallan nos hacen una devolución para que tu puedas mejorar para la próxima fiesta. Como estuvo, que falto, si cumpliste en tiempo y forma, los horarios, si no respetas los horarios estás complicando todo el sistema de trabajo." (Carla, delegada institucional, Diario de campo, extracto de diálogo, 1/10/2016).

Podemos relacionar este proceso de redistribución equitativa producto del trabajo comunitario con el concepto planteado por Godelier de don caritativo (Godelier, 1996:298). Para este autor, en la actualidad, ante la amplitud de los problemas sociales y la manifiesta incapacidad del mercado y del Estado para resolverlas, el don está en situación de volver a convertirse en una condición objetiva, necesaria para la sociedad, y para su reproducción. Este don caritativo funcionaria para la comunidad imaginada de Aiguá cómo idealización, sin un cálculo a priori de ganancias, pero sí, junto a los diversos sentidos de pertenencias que se expresan, como una fuerza que la dinamiza y la fortalece. Para Godelier al idealizarse, el don "sin cálculo", el don caritativo funcionaría en el imaginario como el último refugio de una solidaridad, de una generosidad en la distribución, que habría caracterizado a otras épocas de la evolución de la humanidad. De esta manera el don caritativo se hace portador de una utopía que puede proyectarse tanto hacia el pasado, cuando las instituciones de Aiguá no podían hacer frente a sus problemas económicos, a como hacia el futuro, una comunidad más unida e integrada que lucha contra esa amenaza en común.

\section{Discusión}


Según lo que pudimos ver durante los días de celebración, el repertorio simbólico (Turner, 1967) que se despliega desde la organización de la Fiesta del Jabalí refiere a elementos que son percibidos como propios: danzas típicas, gastronomía criolla, la caza del jabalí, la solidaridad de la red institucional, demostraciones y deportes de "aventura" típicos de la sierra como el motocross, mountain bike o parapente, feria de productos artesanales y objetos de la zona. Existe una continua explicitación de "lo que es la vida serrana" o "la solidaridad del aigüense". A su vez, dentro de las diferentes miradas se percibe la presencia del jabalí como un cohabitante del entorno y al mismo tiempo un peligro o amenaza a la comunidad. Son estos elementos asumidos y reproducidos por los organizadores como propios de la "identidad aigüense" fomentada en la fiesta.

Al respecto y volviendo a lo expuesto por Anderson (2000) las comunidades no deben analizarse como verdaderas o falsas, sino por el estilo con que son imaginadas. Y en este sentido es posible pensar que durante los días que dura la Fiesta del Jabalí se ponen en juego procedimientos y acciones que de alguna manera refuerzan el sentimiento de comunidad y al mismo tiempo de pertenencia a dicha comunidad. También coincidimos con Silla (2011) en la medida de que parece haber una intención implícita y explícita (mediante el Reglamento de la Coordinadora) de fomentar la construcción y el sentido de pertenencia a la comunidad representada por las I.U.A como una forma de darle cohesión, orden y legitimidad al accionar del grupo. Pero esto no necesariamente quiere decir que los integrantes de las I.U.A se auto perciban con una misma identidad. Es interesante entonces pensar en la posibilidad de separar, como indica Grimson (2011), los procesos de identidad de los sentimientos de pertenencia, y al mismo tiempo pensar esas descripciones como ambiguas o superpuestas, en palabras de Silla (2011), ya que una misma persona puede presentarse desde sus diferentes roles o lugares de pertenencia.

Como mencionamos antes, la idea del jabalí como un animal invasor y perjudicial está fuertemente fomentada desde la organización de la fiesta. Es por esto necesario analizar este problema desde la propuesta de Sordi (2017), es decir romper con la idea binaria de naturaleza/cultura o doméstico/salvaje y pensar a la feralidad del jabalí como un "operador conceptual". En ese sentido es interesante el rol que ocupan las entidades estatales en la fiesta. Mencionamos la participación del Municipio de Aiguá en la "Coordinadora" y la articulación de ésta con la Intendencia de Maldonado. Pero también es relevante la participación del gobierno nacional a través del MGAP y como éste contribuye y legitima la idea del jabalí como plaga. Este Ministerio participa activamente el domingo por intermedio de técnicos que etiquetan a los animales y recogen muestras de los jabalíes con el fin de analizarlas y detectar posibles enfermedades. El procedimiento de toma de muestras se realiza a la vista del público presente, además de los equipos de cacería, y sucede luego de la actuación del jurado del concurso de caza.

Para Sordi (2017) los agentes públicos, en este caso partiendo del decreto que categoriza como plaga al jabalí, "colocaron el mal en el bicho". Para el autor el hecho de que el Estado establezca una alianza con ciertos agentes previamente vistos como marginales de la legalidad, en nuestro caso los cazadores, revela que esos dispositivos de domesticación de la agencia entre humanos hacia los animales no serían mecanismos de erradicación simplemente de su feralidad, más bien, serían formas de evocar el devenir de lo salvaje en el jabalí (Sordi, 2017, p.287). Tal parecería ser el caso del papel que juega el MGAP como representante del Estado uruguayo en la fiesta. Es claro que la acción que lleva adelante en este momento de la fiesta es la de reforzar la idea, ya fuertemente expresada en la gráfica, comunicados de prensa, 
entrevistas a los organizadores entre otros, de que el jabalí es una plaga y un potencial transmisor de enfermedades.

Las vecinas y vecinos de Aiguá, que integran las Instituciones Unidas ya tienen un ejercicio sostenido de comunidad, con mecanismos, procedimientos, fechas, momentos específicos durante el año. Este ejercicio continuado ha madurado y tomado la forma de un reglamento de funcionamiento para la gestión de la fiesta por partes de las instituciones Unidas. Tienen claro cuando nació el grupo, quienes lo integran, como deben vincularse, los fines comunes y los valores que los justifican. Las I.U.A funciona como una alianza de auto adscripción fuertemente reglamentada y al integrarse como tal se dan por hecho varias cosas porque están definidas en el propio Reglamento. Podemos hablar entonces de una ritualización ya que las vecinas y vecinos de Aiguá ya saben qué es lo que sucede y va a suceder cada año en la primera semana de octubre. Saben que significa la fiesta, el beneficio económico a primera vista y la posibilidad de unirse por un bien común. Y saben que para que eso suceda deben darse una serie de acciones previas fuertemente reglamentadas. Por ejemplo, que hay una organización que le da forma no sólo al trabajo, a la recaudación y su posterior distribución, sino también que dicha organización opera, luego de negociaciones y acuerdos, sobre los contenidos, valores y los significados compartidos que le darán profundidad simbólica a la fiesta.

También podemos decir que la fiesta del jabalí tuvo un proceso de división o mitosis ya que comenzó como un concurso de caza, La Cacería, y al pasar los años se desarrolló en su seno también un ritual de fortalecimiento del sentido de comunidad, de pertenencia a Aiguá a través del trabajo colectivo y comunitario por intermedio de sus Instituciones Unidas. Pero lo que parece surgir, luego del trabajo de campo, es que son dos grupos diferentes con procesos de auto adscripción diferentes. De todas formas, ambos grupos y rituales, el de la solidaridad y la cacería, funcionan de manera sistémica vinculados entre sí, dependientes uno de otro ya que se necesitan y se retroalimentan.

\section{Conclusiones}

Nuestro pasaje por la fiesta del Jabalí en varias ediciones fue muy enriquecedor y esclarecedor en varios aspectos. Por un lado, nos permitió conocer de primera mano las estrategias de una pequeña población serrana para afrontar problemas bien concretos como pueden ser la invasión de un animal considerado perjudicial para la comunidad, y al mismo tiempo la falta de recursos económicos para desarrollar los servicios sociales en beneficio de la comunidad. Pero la manera y los sentidos de dichas estrategias son propias de Aiguá y es necesario verlas desde una perspectiva histórica como producto de dinámicas locales y coyunturas políticas, institucionales, sociales que se expresan a nivel cultural.

Lo que percibimos y analizamos sobre esta celebración nos invita a pensar los procesos que vinculan a humanos y animales más allá de la mirada puramente biológica o sanitarista sino también en relación con otros procesos, como pueden ser los económicos, políticos, sanitarios, identitarios o comunitarios entre otros.

En definitiva, consideramos que vale la pena el pensar conceptos vinculados a la identidad en escalas menores, en vez de pensarlas sólo desde una escala nacional/global. Creemos fundamental seguir abordando estos temas desde miradas más locales, como ejercicio teórico antropológico, pero también para poder dar cuenta de la complejidad cultural de procesos locales y como esas pequeñas localidades resuelven problemas en sus propios términos. 


\section{Referencias}

Anderson, B. (2000). Comunidades imaginadas: reflexiones sobre el origen y la difusión del nacionalismo. México: Fondo de Cultura Económica.

Da Matta, R. (1997). Carnavais, paradas e procissões: reflexões sobre o mundo dos ritos. Religião e Sociedade, 1, pp. 3-30.

De Giorgi, A. (2002). El magma interior. Montevideo, Uruguay: Trilce.

Grimson, A. (2011). Los límites de la cultura. Crítica de las teorías de la identidad. Buenos Aires, Argentina: Siglo XXI.

Grimson, A. (2001). Interculturalidad y comunicación. Bogotá, Colombia: Grupo Editorial Norma.

Hammersley, M. y Atkinson, P. (2001). Etnografía. Métodos de investigación. Barcelona, España: Editorial Paidós.

Homobono, J. (2004). Fiesta, ritual y símbolo: epifanía de las identidades. Cuadernos de Antropología-Etnografía, (26), pp. 33-76.

Lombardi, R., Geymonat, G. y Berrini, R. (2015). El Jabalí en el Uruguay. Problema, desafío y oportunidad. Montevideo, Uruguay: Forestal Atlántico Sur, Weyerhaeuser Productos.

Oliven, R. (1999). Nación y modernidad. La reinvención de la identidad gaúcha en el Brasil. Buenos Aires, Argentina: Editorial Eudeba.

Silla, R. (2011). Colonizar Argentinizando. Identidad, fiesta y nación en el Alto Valle Neuquén. Buenos Aires, Argentina: Editorial Antropofagia.

Sordi, C. (2017). Presenças Ferais. Invasão biológica, javalis asselvajados (Sus scrofa) e seus contextos no Brasil Meridional em perspectiva antropológica (Tesis Doctoral). UFRGS. Porto Alegre.

Turner, V. (1980[1967]). La selva de los símbolos. Madrid, España: Editorial S.XXI.

Yamamoto, D. (2017). Wild Boar. Londres, Inglaterra: Editorial Reaktion Books. 